\title{
Cost Benefit Analysis of Procurement Systems and the Performance of Construction Projects in East Malaysia
}

\author{
Odhigu Festus Onosakponome, Azhar Yahya, Nazatul Shima Abdul Rani, Junaid M. Shaikh* \\ School of Business, Curtin University Sarawak (Australian University), Miri Campus, \\ CDT 250, 98009 Miri, Sarawak, Malaysia \\ *junaid.s@curtin.edu.my
}

\begin{abstract}
This research investigated the impacts of procurement systems on the performance of construction projects in East Malaysia. Construction project outcome may be measured in terms of time, cost and quality achieved. Project clients demand and want best value for their money and they want their projects to be completed on time, within budgeted cost and at appropriate quality or specification. The sample in this research consists of 58 participants that work in a construction companies/industry. 90 questionnaires were distributed, 69 were successfully returned and 58 were fully completed. The sample comprises project clients/owners, project managers, consultants and construction workers. However, due to the fact that the time allocated for this research is limited and it is of qualitative in nature for which the sample size is less important (Kumar, 2005). The aim of using project clients, project managers, consultants and construction workers from different companies is because they work under different circumstances, which will ensure all questions are answered from different perspective. Therefore, the researcher distributed questionnaires randomly among the participants in different construction companies. This also minimises any bias towards any particular company. The key findings and conclusions from literature review and the analysis of results of questionnaires issued to project clients, projects managers, consultants and construction workers showed that traditional procurement system benefits cost and quality but at the expense of time. In other words, traditional procurement system has positive impacts on project objectives of cost and quality and negative impact on project time. Design and build procurement system benefits cost and time but at the expense of quality and this implies that the impacts of design and build procurement system on project objectives of cost and time are positive with negative impact on project quality.
\end{abstract}

Keyword: Procurement system, performance, construction project, business, cost benefits

\section{Introduction}

Construction projects involve different parties, various processes and different stages of work with the aim of achieving project objectives and success (Takim and Akintoye, 2002; Cheung et al., 2001). The degree of construction projects success and performance will depend on the type of procurement system chosen and this will include managerial, financial, technical and the project organization performance of the parties to the construction process. Construction project outcome may be measured in terms of time, cost and quality achieved and construction project owner decision impact these superlative value criteria, is that of selecting the appropriate procurement system and contractor (Takim and Akintoye, 2002). However, majority of clients in Malaysia, both experienced and inexperienced clients totally rely on body of experts for advice on the overall management of their projects, and the more specific task of selecting procurement systems, with the result that incorrect decisions are often taken in most situations with unfortunate consequences. This practice is in alignment with Mortledge et al. (2006) argument about clients' behaviour on procurement systems selection. Appropriate procurement systems are needed to help achieve optimal solutions in terms of cost, time, quality and to contribute positively to other performance parameters. This research investigates the impacts of procurement systems on the performance of construction projects in East Malaysia.

\section{Review of Literature}

Procurement is vital in achieving project objectives of time, cost and quality. Effective planning is fundamental to project success, and decisions taken at the earliest stages of project development will have the most impact on the construction work and its delivery and operation (Best and Valence, 2002). 
Construction Management: The construction industry makes a vital contribution to the social and economic development of every country and it is one of the backbones of the economy of many countries (Rwelamila, Talukhaba and Ngowi, 2000; Cheung et al., 2001; Best and Langston, 2006). Construction management is a discipline and management system specifically created to promote the successful execution of projects for project sponsors or clients. Moreover, construction project outcome may be measured in terms of time, cost and quality achieved and construction project owner decision impact these superlative value criteria, is that of selecting the appropriate procurement system and contractor (Doloi, 2009; Hong Kong Housing Authority, 2000; Lau and Rowlinson, 2009).

Procurement Management: Procurement management is a key component of project management. The procurement of construction project is vast in scope because it involves the gathering and organizing of myriads of separate individuals, firms, and companies to design, manage and build construction products such as houses, office buildings, shopping complex, roads, airports, bridges, and stadiums etc for specific client. Project Management Institute $(2004,269)$ indicates that "procurement management is the process to purchase or acquire the products, services or results needed from outside the project team to perform the work".

Construction Projects: The six phases of construction project life cycle as identified by Bennett (2003) are discussed below:

- Pre-Project Phase: A construction project begins with an idea, a need, and a desire to improve productivity. In this phase, the project owner decides on the project delivery system that will be used (Egbu and Ilozor, 2007)

- Planning and Design Phase: In this phase, the project is well defined, stating its scope and objectives, and cost (Wysocki et al., 2000)

- Contract Selection Phase: In this phase, contractors will consider some factors if they will bid for the project or not. If a contractor finds the prospective project attractive, it will require a series of planning steps will be carried out, including studies of various methods and equipment that would be employed and the development of a preliminary project programme setting forth an approximate time schedule for each major activity (Gould and Joyce, 2009; Pryke, 2009)

- Project Mobilization Phase: Bonds, licences and insurances are secured in this phase. A detailed programme for the construction project activities, project budget, system for tracking projects costs are prepared and established (Bennett, 2003). Next the worksite is organised, with provisions for temporary buildings and services, access and delivery, storage areas and site security. The process of obtaining materials and equipment are incorporated into the project (Gould and Joyce, 2009)

- Project Operations Phase: This is where the execution of the project activities takes place on the construction site. It involves monitoring and control, resource management and documentation and communication (Gould and Joyce, 2009; Uher and Loosemore, 2004)

- Project Closeout and Termination Phase: Project closure occurs once all of the work or activities of the project is finished and all the outputs of the project has been delivered and accepted by the sponsor (Meredith and Mantel, 2006)

Construction Project Performance: Navon (2005) considered control system as an important element that identifies factors affecting construction project effort. Project time is a key factor that serves as an indicator for assessing the performance of the construction project and efficiency of the project organisation. Pheng and Chuan (2006) identify that, human factors play an important role in determining the performance of a construction project and projects generally.

Construction Project Procurement Systems: The selection of procurement system for construction projects should be based on the principles that support best value for money. Selecting a procurement system for construction projects is inherently subjective and the decision is often intuitively based on the previous experience and knowledge of the client or decision-makers (Cheung et al., 2001; Luu, Ng, and Chen, 2003). Procurement system shows the interaction between the design and construction, and 
sometimes the funding and operation for which the project is managed. It identifies the fundamental issues of the relationship between the main elements of the project. Masterman (2002) classifies project procurement systems into several categories based on the relationship and critical interaction between design and construction responsibilities. The categorization of the various project procurement systems are as follows:

Traditional procurement system (TPS): In this procurement system, the design and the construction are carried out by separate organisations. Masterman (2002) identifies some basic characteristics of traditional procurement system, which are:

- Project delivery is a sequential process.

- The design of the project is largely completed before work commences on site.

- The responsibility for managing the project is divided between the client's consultants and the contractor, and there is therefore little scope for involvement of either of the parties in the other's activities.

- Reimbursement of the client's consultants is normally on a fee and expenses basis, whereas the contractor is paid for the work completed on admeasure or lump sum basis.

There are four stages of traditional procurement system which are preparation, design, tender and construction.

Design and build procurement system (DBPS): In DBPS, the responsibility of the design and the construction is on single organisation. The client signs only one contract, thus this form is the most straightforward from the perspective of responsibility and communication. The organisation in charge of the project will likely deliver the greatest performance benefits to the client through innovation, standardisation and integrated supply chain. Furthermore, many surveys have established that clients perceive the design and build system as providing better value for money, and giving rise to less disputes than other procurement systems, and the surveys also suggest that, an experienced client with a clear brief can use it satisfactorily with projects of most sizes.

Construction management procurement system (CMPS): Construction management is where the management service is provided by a fee-based consultant, a specialist construction manager or a contractor and where all construction contracts are directly agreed between the client and the trade (package) contractors. The following are the characteristics of construction management identified by Masterman (2002).

- The construction manager is appointed as a consultant during the initial stages of the project and has equal status to the members of the design teams.

- Reimbursement is made by means of a lump sum or percentage fee for management services.

- The physical construction of the project is carried out by works, or package, contractors who are employed by the client and co-ordinated, supervised and administered by the construction manager.

Management contracting procurement system (MCPS): Management contracting is a process whereby an organisation, normally construction based, is appointed to the professional team during the initial stages of a project to provide construction-management expertise under the direction of the contract administration. This procurement system is a fast track procurement option which overlaps the design and the construction stages and allows early elements of the construction process to be commenced before design has been completed. The management contractor employs and manages works contractors who carry out the actual construction of the project and he/she is reimbursed by means of a fee for his/her management services and payment of the actual prime cost of the construction (Masterman, 2002). Moreover, the management contractor is engaged to manage the overall contract in return for a fee. The management contractor can therefore be appointed early in the design and can advise on buildability and programming. In addition to the contract with the management contractor, the contracts for the individual work packages are between the management contractor and the individual subcontractors (Gould and Joyce, 2009). 


\section{Research Methodology}

It is significant for researchers to consider the issue of the number of the respondents and who will be included in the research (Sarantakos, 2005). The sample in this research consists of 90 participants that work in a construction companies/industry, however, only about 69 were successfully returned and 58 were fully completed $(64 \%$ response rate from the survey). The sample comprises project clients/owners, project managers, consultants and construction workers. However, due to the fact that the time allocated for this research is limited and it is of qualitative in nature for which the sample size is less important (Kumar, 2005). The rational for choosing these samples are due to different companies is because they work under different circumstances. And this is to ensure that questions are not answered from the same perspective. Therefore, the researcher distributed questionnaires randomly among the participants in different construction companies. This also minimises any bias towards any particular company. Questionnaire instrument was chosen as the method of collecting primary data. Questionnaire is a self-report data-collection instrument filled out by research participants (Burke and Larry, 2000). The content and organisation of a questionnaire will correspond to the researcher's research objectives. There are 21 questions comprises yes and no questions and open-ended questions. Questionnaires are given to project clients, project managers, consultants and construction workers in different construction companies. A pilot test provides the researcher an opportunity to identify confusing and ambiguous language, and to obtain information about possible patterns of results (Wiersma and Jurs, 2005).

\section{Findings and Discussions}

Positions of Respondents: The percentage of the respondents are well spread which represents a significant amount of respondents for analysis. 19 (33\%) of the respondents are project managers that have wealth of knowledge in project management while 16 (28\%) are project clients/owners that have the responsibility of taking procurement options with advice from experts. $13(22 \%)$ are consultants that are experts and professionals that advice project clients on the best course of procurement strategy to take in project executions whereas $10(17 \%)$ are construction workers with different experiences and responsibilities in their organisations. The respondents are stakeholders in the construction process that has influence on the outcomes of the project. This expression is consistent with the literature in that a stakeholder is an individual or group, inside or outside the construction project, which has a stake in, or can influence, the construction performance (Takim and Akintoye, 2002).

Working Experience: All respondents met the minimum criterion of two years project management experience and we observed that $23(40 \%)$ of the respondents have more than fifteen years of project management experience and this is to say that they have good knowledge of project management processes, techniques, tools and objectives. 20 (34\%) of the respondents have 6-15 years of project management experience which indicates respondents' wealth of knowledge in construction projects management in the construction industry. The expertise, skills, experiences and knowledge of project term will enhance project performance. The literature points out that the project manager and project team members should have sufficient knowledge, people skills, organisational skills, team participation skills and an understanding to undertake the various activities as defined in the project (Takim and Akintoye 2002; Cheung et al., 2001; Masterman, 2002). This aligns with Morris and Pinto (2004) that say, a good performing project team is able to incorporate technical aspect as well as social skills to generate synergies, solve conflicts, and ensure learning.

The Choice of Procurement Systems Influences Construction Project Objectives: Out of total, 48 (83\%) of the respondents believed that the choice of procurement systems in construction project execution influence project objectives while $10(17 \%)$ are of the opinion that the choice of procurement systems in construction projects do not influence construction project objectives. This information indicates that the choice of procurement systems has impacts on construction projects performance or objectives. The selection of a suitable procurement system is critical to the success of any project. There is strong support (83\%) with the literature that procurement is a key factor contributing to overall client satisfaction and project success. When considering a procurement system to be use in construction project, there is no simple formula that is applies.

TPS vs. Time: $44(76 \%)$ of the respondents agreed that TPS does not favour construction project objective of time whereas 14 (24\%) disagreed. TPS does not favour project objective of time as a result of its sequential or linear approach. In TPS, the design of the project is largely completed before work 
commences on construction site. These findings are in harmony with Masterman (2002); Walker and Rowlinson (2008) that say, the sequential, fragmented and confrontational nature of TPS can result in lengthy design and construction periods. Project time overruns which is the impact of TPS on project objective of time occurs in project of all sizes but more in big projects. However, TPS provides clear accountability and better design by the client due to more time available for the client and project team in the pre-contract phase to examine and review the design before construction.

TPS vs. Cost: 44 (76\%) of the respondents believed that TPS favour construction project objective of cost whereas $14(24 \%)$ did not believe that TPS favour project objective of cost. TPS provides cost certainty to the project client at the early stage of the construction project. It gives the project client a better and more competitive price because the design has been fully developed prior to tendering. There is clear accountability and cost monitoring at all stages of the construction process. TPS eliminates design and construction ambiguity which often cause the contractors to inflate cost unnecessarily. Moreover, where bill of quantity is used, the bidding tend to be more fair and result to lower project cost (Masterman, 2002).

TPS vs. Quality: 45 (78\%) of respondents indicated that TPS favour project objective of quality whereas $13(22 \%)$ indicate that it does not favour construction project quality. TPS favours construction project objective of quality because the TPS provides more time for the project client and consultants to review and completely develop the design and specifications before construction commences. These responses are aligned with the literature in that the use of TPS provides a higher degree of certainty that quality and functional standards will be met than when using other procurement systems (Masterman, 2002; Gould and Joyce 2009; Walker and Rowlinson, 2008).

DBPS vs. Time: Out of total, 45 (78\%) of respondents agreed that design and build aid the realisation of time objective of project whereas $13(22 \%)$ disagreed. DBPS is a relatively fast system of procurement because the design and construction are integrated. The construction time is reduced because design and construction proceed in parallel. This system allows detail design and construction run in parallel and concurrently to each other, thus reducing the overall project period. This is in accordance with Masterman (2002) and Gould and Joyce (2009) that say, the overlapping activities in design and build procurement system enable shorter overall project periods to be achieved. The overlapping activities in DBPS happen in all project sizes but better achieved in big and medium projects. Project location could influence the degree of overlapping activities of design and build procurement system.

DBPS vs. Cost: $38(66 \%)$ of the respondents stated that DBPS do enhance the achievement of construction project objective of cost while $20(34 \%)$ do not agree to that. This indicates that DBPS benefit the project cost. Supported to this Gould and Joyce (2009), provided that the client's requirements are accurately specified, certainty of final project cost can be achieved. In addition, significant cost saving is achieved in design and build procurement system through the reduction of the overall project development period. The application of the contractor knowledge, expertise and experiences in construction management could simplify design and work which could lead to cost reduction. The certainty of final project cost in DBPS is more realistic in small and medium projects than big projects. Location of project plays a key role in determining the actual project cost in regards to availability and cost of project materials and resources.

DBPS vs. Quality: 43 (74\%) of respondents believed that DBPS do not enhance the achievement of project quality whereas $15(26 \%)$ believed that it does enhance the realization of project quality. In this procurement system, the client has no direct control over the contractor's performance and the client has little say in the choice of specialist sub-contractors. In addition, the contractors assume responsibility for the fitness for purpose of the finished product/deliverables and build ability of the detailed design. Given the design and construction of the project to a single contractor has caused the client to lose control and supervision of the design and construction work. At times the contractor tend to cut corners in order to maximize profit and this occur when the contractor feel that their quotation price is under priced during tendering and this will have negative impact on project quality. The loss of direct control and supervision of the project client over the contractor's performance and the choice of specialist sub-contractor is more prevalent in big and medium projects than small projects. These have impacts on the project quality. The impact is more on project quality where the project client is far from the location of the project. 
CMPS vs. Time: 37 (64\%) of the respondents are on the opinion that CMPS benefit project objective of time whereas $21(36 \%)$ of the respondents disagreed. This procurement system is used based on the ground that the contractor has the expertise, experience, knowledge, and competency to manage the design and construction of the project. This is in alignment with Walker and Rowlinson (2008) that say, CMPS provides services for construction planning, coordination and supervision of those who have direct contracts with the owner to carry out operational work. CMPS allows early start of construction on site as possible, long before tenders have been invited for some of the works packages. These factors bring a considerable reduction of the overall construction project period.

CMPS vs. Cost: The results shows that construction management as a procurement system does not benefit the project cost objective and $43(74 \%)$ of respondents agreed to it whereas 15 (26\%) did not agree. The project owner will appoint a construction manager to manage the overall contract in return for a management fee. Moreover, the fact that the client enters into direct contracts with individual work package contractors enables a high level of immediate cost control to be achieved and also ensures that the works contractors' cash flows are improved as a result of receiving direct payments from the client rather through an intermediary (Masterman, 2002). However, the cost of the project is actually the cost quoted by the package contractors. The only additional cost to the project is the consultant fee or management fee that the project client pays the construction manager. The project cost quoted by package contractors are more realistic in small and medium project than big projects because escalation of materials prices occurs more in big projects as a result of long construction period. Cost of projects in rural area tends to be higher because of transportation cost of project materials and equipment.

CMPS vs. Quality: $41(71 \%)$ of the respondents indicated that construction management as a procurement system benefit project quality whereas $17(29 \%)$ of the respondents did not believe that it benefits project quality. The construction manager is responsible for quality of work and materials on construction site. The construction manager tends to be concern with the quality and standard of work of package contractors. In addition, construction manager expertise, experience and knowledge enhance high quality of work/activities and materials selection. The high level of knowledge and experience of the construction manager contributes to a high quality and standard of deliverables or completed products of the project. The high project quality and meeting client specifications in CMPS is achieved in all project size as a result of the construction manager expertise, knowledge and experience.

MCPS vs. Time: This question sought if MCPS enhances the attainment of construction project objective of time. Management contracting does enhance the achievement of project objective of time. 41 (71\%) of the respondents agreed that it enhances the attainment of objective of time whereas 17 (29\%) of the respondents disagreed. These findings are supported in literature that MCPS is a fast track procurement system which overlaps the design and the construction stages and allows early elements of the construction process to be commenced before design has been completed (Masterman, 2002; Walker and Rowlinson, 2008). The overlapping of activities in the design and construction phases in management contracting procurement system shorten the project time, this occurred in project of different sizes, irrespective of the project geographical area. There is a high degree of flexibility that is built into this procurement system, which enables delays to be overcome or reduced, changes to be absorbed and rescheduling of works packages to be implemented. The expertise, knowledge, experience and competency of the management contractor enhance effective and efficient coordination of schedule, activities/works, plants, materials and manpower and thus reduces overall construction period. These findings are aligned with the literature that management contracting enables commencement of the project to be accelerated, which in turn, should enable earlier completion to be achieved than when using traditional system (Masterman, 2002; Walker and Rowlinson, 2008; Gould and Joyce, 2009).

MCPS vs. Cost: This is to determine the impacts management contracting has on project cost. The results show that management contracting does not enhance the attainment of the project objective of cost and $38(66 \%)$ of the respondents supported it whereas $20(34 \%)$ did not support it. This is in harmony with Masterman (2002) that says current research indicates that the project costs incurred when using MCPS are higher than those generated when using the traditional or design and build. This situation results from high tenders submitted by works contractors, as a result of onerous contract conditions and high levels of risk imposed by management contractor, and the duplication of management and common services costs brought about by the presence of both the management contractor's and package contractor's site organisation. Additional cost to the project is the consultant fee or management fee that the project client pays the management contractor. The higher project cost incurred using MCPS is more 
prevalent in big and medium projects than small projects and more in project location where there are inadequate of project materials.

MCPS vs. Quality: The figure shows that $45(78 \%)$ of the respondents agreed that management contracting enhances the attainment of construction project objective of quality whereas $13(22 \%)$ of the respondents disagreed. The early involvement and advice that is obtained from management contractor on design, build ability, programming and material availability, together with general construction expertise enhance the quality of the project deliverables. The management contractor is seriously concern with the quality and standard of work of package contractors. Furthermore, the expertise and the experience of the management contractor enable him to be proficient and effective in ensuring high quality of completed project deliverables or products. Fitness for purpose of project deliverables that is achieved in using MCPS occurred in project of different sizes and project location.

The Best Procurement System: Total 18 (31\%) of the respondents supported design and build whereas $14(24 \%)$ of the respondents supported construction management and management contracting. 12 (21\%) of the respondents supported traditional. Their views and opinions are based on experiences and knowledge. Procurement strategy is the outcome of a series of decisions which are made during the early stages of a project and it is one of the most important decisions facing the project client. No single procurement system can be applied universally on all construction projects. The responses are aligned with the literature in that different client has differing needs and requirements whereby construction projects vary so considerably, in every respect, that no single system of procurement can be suitable for every project (Luu, Ng, and Chen, 2003; Cheung et al., 2001). Each procurement system is chosen for a particular project based on certain criteria and those criteria are listed in table 1. A successful procurement system is one which leads to a completed project which meets the client's objectives. In addition, the selection and use of an appropriate procurement system contributes significantly to the success of a construction project (Mortledge et al. 2006). Understanding needs of different project types will enhance the development of appropriate procurement strategies to meet the needs of these projects (Walker and Rowlinson, 2008).

\section{Table 1: Criteria Clients Use in Selecting Procurement Systems}

1. Time (speed)

2. Quality level

3. Risk allocation/avoidance

4. Flexibility to change design during both design and construction period

5. Responsibility

6. Complexity

7. Price competition

8. Certainty of cost and time

9. Disputes and arbitration

10. Project type

11. Client's experience

12. Experienced contractor availability

13. Client's willingness to be actively involved

14. Project site location

15. Client's trust in other parties

16. Political constraints

17. Project size

18. Regulatory impact

19. Market competitiveness

20. Client's requirement for value for money

21. Material availability

22. Client's financial capability 
The selection process requires experienced judgement, current market conditions, contractor capability to execute the contract, project objectives, and project requirements and characteristics. Several previous studies have identified number of factors influencing the selection of procurement system in construction. The Table 2 results are in similarity with literature in that the common criteria concerning the choice of procurement systems include time, certainty, flexibility, quality, complexity, risk, price competition, responsibility, and dispute and arbitration. The selection criteria for project procurement will influence which procurement system should be used in a particular project. Selecting a procurement system is a daunting task for the client due to various factors governing a construction projects. Different client has differing needs and requirements whereby construction projects vary so considerably, in every respect, that no single system of procurement can be suitable for every project (Luu, Ng, and Chen, 2003; Cheung et al., 2001). When project client, or consultant and decision-makers are selecting a procurement system for a project, their previous experience plays an influential role. This question sought to determine the main criteria clients use in selecting procurement systems. The above table shows respondents answers on the main criteria clients use in selecting procurement systems in their project executions.

Table 2: Major Criteria that Influence Procurement Systems Selection
1. Client's willingness to be actively involved
2. Flexibility to change design during both design and construction period
3. Risk allocation/avoidance
4. Project size
5. Client's experience
6. Certainty of cost and time
7. Experienced contractor availability
8. Client's trust on other parties
9. Client's requirement for value for money
10. Project type

This finding are supported by the literature that the most common criteria influencing the choice of procurement system include time, controllable variation, complexity, quality level, price certainty, competition, responsibility, risk avoidance, price completion, government policy and client's familiarity in a procurement system (Luu, $\mathrm{Ng}$, and Chen, 2003). Since the selection of procurement system is influence by client characteristics, project requirements and external environment, the procurement selection parameters should represent client characteristics, project requirements and external environment and these should be considered in decision making in regards to choosing a procurement system.

Furthermore, Walker and Rowlinson (2008) indicate that, the main drivers that influence procurement choice relates to project characteristic (project type), project sponsors' expectations and their perceptions of what contributes value, and the extent to which the rules and methods to deliver the project may be known. In order for project to be successful, the procurement system should address the technical features of the project and client's and contractor's needs and other relevant stakeholders' expectations. Chan and Kumaraswamy (2002) identify that construction time is increasingly important because it often serves as a crucial benchmarking for assessing the performance of a project and efficiency of the project organisation. The findings in table 3 supports the literature in that people, cost, time, quality, safety and health, environment, and communication as factors that affect construction performance (Cheung et al., 2004). This aligns with Thomas et al. (2002) that say, factors that affect construction project performance are financial stability, progress of work, standard of quality, health and safety, resources, relationship with clients, relationship with consultants, management capabilities, claim and contractual disputes, relationship with subcontractors, reputation and amount of subcontracting. 


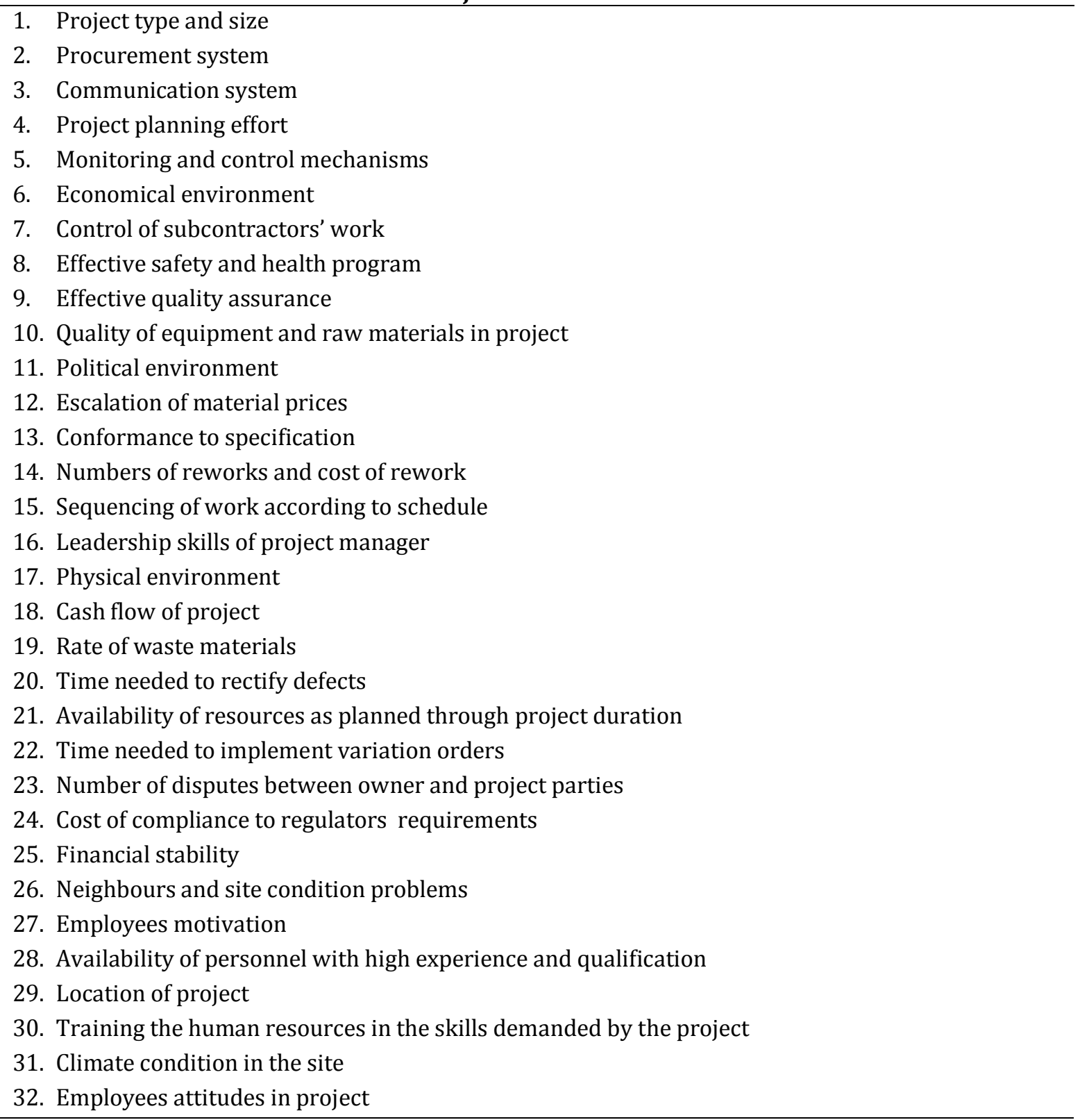

The results in table 4 show the major factors that affect construction project performance from respondents. Procurement system seems to be an important factor that affects construction project performance. Monitoring and control mechanisms, leadership skills of project manager really affect project performance. A project manager with strong leadership skills, could monitor, control, and manage project performance with high quality. Navon (2005) is in agreement that, control system is an important element to identify factors affecting construction project effort. Furthermore, human factors play an important role in determining the performance of a construction project and projects generally. Pheng and Chuan (2006) is in alignment that human factors play an important role in determining project performance. Availability of personnel with high experience and qualification could lead to better performance of time, cost and quality, productivity and safety of construction projects. This perspective supports the literature in that availability of personnel with high experience and qualification affects strongly on quality performance of construction projects (Cheung et al., 2004). 
1. Availability of resources as planned through project duration

2. Financial stability

3. Quality of equipment and raw materials in project

4. Employees motivation

5. Availability of personnel with high experience and qualification

6. Monitoring and control mechanisms

7. Leadership skills of project manager

8. Project planning effort

9. Escalation of material prices

10. Procurement system

11. Sequencing of work according to schedule

12. Cash flow of project

13. Conformance to specification

14. Employees attitudes in project

\section{Summary of the Findings}

Impacts of Procurement Systems on Project Objectives of Time, Cost and Quality: The findings on the impacts of procurement systems on project objectives of time, cost and quality are summarized under each procurement system that was considered in this research. Table summarises the findings for this study.

Table 5: Procurement Systems vs. Project Objectives

\begin{tabular}{lcccc}
\hline & TPS & DBPS & CMPS & MCPS \\
\hline Time & -ve & +ve & +ve & $+v e$ \\
Cost & $+v e$ & $+v e$ & $-v e$ & $-v e$ \\
Quality & $+v e$ & -ve & $+v e$ & $+v e$ \\
\hline
\end{tabular}

If the objective of the company is to speed the project and time is crucial, the TPS is not suitable to be used. If cost saving is the main objective of a construction project, TPS and DBPS able to reduce cost, because the cost estimation are done in detail depending on the project requirement. However, if the quality is the main concern, DBPS is not suitable to be used as procurement system.

Principal Factors and Criteria that Influence Selection of Procurement Systems: The principal factors and criteria are client's willingness to be actively involved, flexibility to change design during design and construction period, risk allocation/avoidance, project size, client's experience, certainty of cost and time, client's requirement for value for money, and project type.

Critical Factors that Affect Construction Projects Performance: The critical factors that affect construction projects performance are

- Availability of resources as planned through project duration.

- Financial stability.

- Quality of equipment and raw materials in project.

- Employees' motivation.

- Availability of personnel with high experience and qualification.

- Monitoring and control mechanisms.

- Leadership skills of project manager.

- Project planning effort.

- Escalation of material prices.

- Procurement system.

- Sequencing of work according to schedule.

- Cash flow of project.

- Conformance to specification.

- Employees attitudes in project 


\section{Suggestions where Each Procurement System could be used}

TPS should be used when

- $\quad$ Product quality is wanted;

- Price certainty is wanted before the start of construction;

- A programme allows sufficient time;

- A balance of risk is to be placed between the client and contractors; and

- A client wishes to appoint designers and contractors separately.

DBPS should be used when:

- A firm price is needed in advance of construction;

- A brief for scope design is unlikely to change;

- A single organisation is required to take responsibility and risk for design and construction; and

- A programme can be accelerated by overlapping design and construction.

CMPS should be used when:

- Flexibility in design is wanted to allow for changes to be made as the process of design and construction are carried out;

- A client and his advisers have insufficient management resources;

- Maximum price competition for the works element is wanted; and

- An early start to construction and early programme of completion, requiring design and construction to proceed in parallel, is wanted.

\section{Conclusions}

TPS benefits cost and quality but at the expense of time. In other words, TPS has positive impacts on project objectives of cost and quality and negative impact on project time. DBPS benefits cost and time but at the expense of quality and this implies that the impacts of DBPS on project objectives of cost and time are positive with negative impact on project quality. Construction management and management contracting procurement systems benefit time and quality but at the expense of cost, this implies that they have positive impacts on time and quality with negative impact on project cost. The above information could be used as a guideline for project clients, project managers, consultants and decisionmakers in making decisions in regards to the choice of procurement systems to be used in construction projects in the construction industry.

\section{References}

Albert, P. C. C., Scott, D, and Chan, P. L. (2004). Factors affecting the success of a construction Project. Journal of Construction Engineering and Management. 130(1): 153-155.

Bennett, F. L. (2003). The management of construction: A project life cycle approach. Oxford: ButterworthHeinemann.

Best, R., and Langston, C. (2006). Evaluation of construction contractor performance: a critical analysis of some recent research. Construction Management and Economics, 24(4): 439-445.

Best, R., and Valence, G. D. (2002). Design and construction: building in value. Sydney: ButterworthHeinemann.

Burke, J., and Larry, C. (2000). Educational research: Quantitative and qualitative approaches. Boston: Allen and Bacon.

Chan, A. P. C. (2002). Framework for measuring project success. Journal of Construction Engineering and Management, 18(3):120-129.

Chan, A. P. C., Scott, D., and Chan, A. P. L. (2004). Factors affecting the success of a construction project. Journal of Construction Engineering and Management, 130(1):153-155.

Chan, D. W. M., and Kumaraswamy, M. M. (2002). Compressing construction durations: lessons learned from Hong Kong building projects. International Journal of Project Management, 20(1): 23-35.

Cheng, E. W. L., and Li, H. (2002). Construction partnering process and associated critical success factors: Quantitative Investigation. Journal of Management in Engineering, 18(4): 194-203.

Cheung, S., Lam, T., Wan, Y., and Lam, K. (2001). Improving objectivity in procurement selection. Journal of Management in Engineering, 17 (3):132-140. 
Cheung, S., Lam, T., Leung, M., and Wan, Y. (2001). An analytical hierarchy process based procurement selection method. Construction Management and Economics, 19(4): 427-437.

Cheung, S., Suen, C. H., and Cheung, K. W. (2004). PMMS: A web-based construction project performance monitoring system. Automation in construction, 13(3): 361-376.

Doloi, H. (2009). Relational partnerships: the importance of communication, trust and confidence and joint risk management in achieving project success. Construction Management and Economic, 27(1): 1099-1109.

Egbu, C., and Ilozor, B. (2007). Construction clients and innovations: an understanding of their roles and impact, in proceedings of CIB World Building Congress, 3259-3267.

Gould, F., and Joyce, N. (2009). Construction project management. 3rd edition. New Jersey: Pearson Education, Inc.

Hong Kong Housing Authority. (2000). Quality Housing: Partnering for change. Public Construction Paper by the Hong Kong Housing Authority.

Hossain, L. (2009). Communications and coordination in construction projects. Construction Management and Economics, 27(1): 25- 39.

Kumar, R. (2005). Research methodology: A step-by-step guide for beginners. $2^{\text {nd }}$ edition. . Frenchs Forrest: Pearson Longman.

Lau, E., and Rowlinson, S. (2009). Interpersonal trust and inter-firm trust in construction projects. Construction Management and Economics, 27(6): 539 -554.

Luu, D. T., Ng, S. T., and Chen, S. E. (2003). A case-based procurement advisory system for construction. Advances in Engineering Software, 34(7): 429-438.

Luu, D. T., Ng, S. T., and Chen, S. E. (2003). Parameters governing the selection of procurement system-an empirical survey. Engineering Construction and Architectural Management, 10(3): 209-218.

Masterman, J. W. E. (2002). An introduction to building procurement systems. $2^{\text {nd }}$ edition. London. Spon Press.

Meredith, J., and Mantel, S. J. (2006). Project management: A managerial approach. New York: John Wiley.

Morris, P. W. G., and Pinto, J. K. (2004). The Wiley guide to managing projects. Hoboken, New Jersey: John Wiley and Sons.

Mortledge, R., Smith, A., and Kashiwagi, D. T. (2006). Building Procurement. Oxford, UK: Blackwell.

Navon, R. (2005). Automated project performance control of construction projects. Automation in Construction, 14(4): 467-476.

Office of Government Commerce. (2003). Project procurement lifecycle the integrated process. Achieving Excellence in Construction Procurement Guide.

Pheng, L. S., and Chuan, Q. T. (2006). Environmental factors and work performance of project managers in the construction industry. International Journal of Project Management, 24(1): 24-37.

Project Management Institute. (2004). A Guide to the Project Management Body of Knowledge. PMBOK Guide. Third Edition. Newtown Square, Pennsylvania USA: Project Management Institute.

Pryke, S. (2009). Construction supply chain management: Concepts and case studies. United Kingdom: Wiley-Blackwell.

Rwelamila, P. D., Talukhaba, A. A., and Ngowi, A. B. (2000). Project procurement systems in the attainment of sustainable construction. Sustainable Development, 8(1): 39-50.

Sarantakos, S. (2005). Social research. $3^{\text {rd }}$ edition. Houndmills, Basingstoke, Hampshire; New York: Palgrave Macmillan.

Takim, R., and Akintoye, A. (2002). Performance indicators for successful construction project performance. School of Built and Natural Environment, Glasgow Caledonian University, City campus. Glasgow G4 OBA, UK.

Thomas, S. N., Palaneeswaran, E., and Kumaraswamy, M. M. (2002). A dynamic e-Reporting system for contractor'sperformance appraisal. Advances in Engineering .Software, 33(6): 339-349.

Uher, T. E.; Loosemore, M. (2004). Essentials of construction project management. Sidney: University of New South Wales Press.

Walker, D. H. T. and Rowlinson, S. (2008). Procurement Systems - A Cross Industry Project Management Perspective. Procurement Systems-A Project Management Perspective. Taylor \& Francis. Oxford.

Wiersma, W. \& Jurs, S. G. (2005). Research methods in education: an introduction. Boston: Pearson

Wysocki, R. K., Beck R. Jr., and Crane D. B. (2000). Effective Project Management. Second edition. Canada. John Wiley \& Sons. 